Review Article

\title{
Measuring the Quality of Life in Patients with Multiple Sclerosis in Clinical Practice: A Necessary Challenge
}

\author{
Karine Baumstarck, ${ }^{1}$ Laurent Boyer, ${ }^{1}$ Mohamed Boucekine, ${ }^{1}$ Pierre Michel, ${ }^{1}$ \\ Jean Pelletier, ${ }^{2}$ and Pascal Auquier ${ }^{1}$ \\ ${ }^{1}$ EA3279, Self-Perceived Health Assessment Research Unit, School of Medicine, Aix-Marseille University, 27 Boulevard Jean Moulin, \\ 13385 Marseille Cedex 05, France \\ ${ }^{2}$ Department of Neurology, Timone University Hospital, 27 Boulevard Jean Moulin, 13385 Marseille Cedex 05, France
}

Correspondence should be addressed to Karine Baumstarck; karine.baumstarck@univ-amu.fr

Received 14 November 2012; Revised 7 January 2013; Accepted 5 February 2013

Academic Editor: Rob Bermel

Copyright (C) 2013 Karine Baumstarck et al. This is an open access article distributed under the Creative Commons Attribution License, which permits unrestricted use, distribution, and reproduction in any medium, provided the original work is properly cited.

While the physical disability aspect of multiple sclerosis (MS) is of great importance, quality of life (QoL) measurements are being considered increasingly important with regard to evaluating disease progression, treatment, and the management of care provided to MS patients. Despite the acknowledged need to consider QoL issues, QoL assessment remains underutilized in clinical practice. These issues should be explored and understood to promote the use of measuring QoL in MS clinical practice. We explore the difficulties for clinicians: choosing and determining the most appropriate QoL measure and how to best integrate QoL measurements into clinical practice. This paper discusses several avenues to provide to clinicians arguments of the clinical relevance and accuracy of QoL instruments and ultimately to enhance the use of QoL measures in clinical practice for MS patients.

\section{Introduction}

While the physical disability aspect of multiple sclerosis (MS), the most common demyelinating disease of the central nervous system in young adults, is of great importance, it is now well recognized that it does not reflect all of the facets that patients consider important in their life. Fatigue, depression, and physical disability are only one aspect of a person's experience with MS; it is well documented that cognitive, emotional, and psychological functions contribute to their quality of life (QoL) [1]. The QoL measurements are being considered increasingly important with regard to evaluating disease progression, treatment and the management of care provided to MS patients $[2,3]$. The US Food and Drug Administration (FDA) and the European Medicines Agency encourage the use of QoL assessment in patients with chronic illnesses $[4,5]$, and several groups have published detailed recommendations for QoL assessment [6, 7]. In MS research, 118 studies that have reported QoL as an outcome were performed with MS patients in the Clinical Trials registry
(ClinicalTrials.gov, December 31, 2012). Despite the acknowledged need to consider QoL issues, QoL assessment remains under-utilized in MS clinical practice [8]. QoL assessment may be considered to be an "unfulfilled promise" [9-11]. Therefore, these issues should be explored and understood to promote both the use and usefulness of measuring QoL in MS clinical practice. Here, we explore the difficulties for clinicians to choose and determine the most appropriate QoL measure, to be convinced by the clinical utility of the QoL assessment implementation in clinical practice and to interpret QoL scores.

\section{Difficulties for MS Clinicians to Choose and Determine the Most Appropriate QoL Measure}

QoL is commonly assessed using self-reported questionnaires [3]. To fully understand and explore the effectiveness of any intervention for the management of MS, it is important to 
have robust, valid, reliable, and universally applied measures [12]. Generic instruments are generally used to compare QoL across different populations, while disease-specific instruments focus on particular health problems and are more sensitive for detecting and quantifying small changes [13]. In MS clinical practice, MS-specific questionnaires are more appropriate due to a better ability to discern QoL differences in patients than the 36-Item Short Form [14].

2.1. A Large Variety of QoL Instruments in MS. A large number of disease-specific QoL instruments have been validated for use in MS patients. The most popular questionnaires are the Multiple Sclerosis Quality of Life questionnaire (MSQOL54) [15], the Functional Assessment of Multiple Sclerosis questionnaire (FAMS) [16], the Hamburg Quality of Life Questionnaire in Multiple Sclerosis (HAQUAMS) [17], the Quality of Life Index-Multiple Sclerosis (QLI-MS) [18], the Multiple Sclerosis Quality of Life Index (MSQLI) [19], the Leeds Multiple Sclerosis Quality Of Life scale [20], the MS Impact Scale (MSIS-29) [21], the Disability and Impact Profile (DIP) [22], the Extension of Quality-adjusted Time without Symptoms of Disease and Toxicity of Treatment [23], and more recently, the Multiple Sclerosis International Quality of Life questionnaire [24]. While some reviews tried to describe the different questionnaires as designed specifically for MS patients $[2,25,26]$, a clinician contemplating these various rules and instruments may be overwhelmed by their level of complexity. The multiplicity of scales used requires describing their psychometrics and the theoretical and conceptual foundations [27]. Clinicians should be provided better guidance and training that includes evidence of the respective contributions of the various available instruments, the degree to which the tools measure what they claim to measure, and their respective strengths and shortcomings.

\subsection{The Psychometric Properties of the QoL Measures: Validity,} and Reliability, Sensibility to Change. High-level requirements for development and metric validation of QoL measures, especially among the most recent instruments, are now well acknowledged $[28,29]$. The definitions of the main psychometric properties are summarized in Box 1. Briefly, we can mention some limitations about the process of validating the QoL questionnaires that may compromise the robustness of the instrument.

First, one important issue concerns the conceptual problems related to the definition of QoL. The researchers should have well-validated questionnaires based on a clear conceptual basis for QoL. One major challenge to explaining the content of the QoL dimensions to be measured is to ensure that the subjects' perceptions are accurately taken into account. Interviews with patients are commonly considered as the best method to capture the patient's perceptions [30, 31] and provide the content of the questionnaire. Few MSspecific QoL questionnaires were exclusively based on the patient's point of view [24].

Second, the "responsiveness" or "sensitivity to change," defined as the ability to detect a meaningful change, is a core psychometric property of a measuring instrument.
Examination of responsiveness requires longitudinal data collection. Given the availability of many QoL instruments, little research has been conducted to test the responsiveness of the QoL tools in MS. The HAQUAMS showed satisfactory responsiveness to change [32], the MSIS-29, MSQOL-54, and FAMS moderately detected change in health status $[33,34]$. Also, clinicians should prefer the use of the HAQUAMS to detect health changes over time of MS patients. Future studies should provide comparisons with responsiveness indices using a direct head-to-head comparison to make the situations in which they were tested comparably.

Finally, another point that should be mentioned is related to the number of available languages of the questionnaire. The MSQOL54 [15, 35-37] and the MusiQoL [24, 38-41] are both available in many languages. These questionnaires were developed simultaneously in a number of countries and thus represent a major strength. These 2 instruments can be applied internationally.

\subsection{The Acceptability of the Questionnaire. Environmental} barriers have been described [42] to explain why QoL measures have not been routinely implemented in clinical practice. Time and resource are both constraints on clinicians whose main role is providing patient care [43]. A great asset of the QoL questionnaire is its acceptability, which concerns the ergonomics of the questionnaire, such as the length of the questionnaire, the paper or electronic format, and the concept of computer adaptive testing.

Some authors have suggested that questionnaires intended for use in clinical populations should be as brief as possible because of the nonadaptability with a clinical evaluation and the difficulties of the concentration and perception faced by patients with a cognitive dysfunction $[8,30]$, such as MS patients. It is common to accept that the average time of completion of a questionnaire should not exceed 10 minutes to be fully compatible with clinical practice. Providing shorter questionnaires in MS QoL measures, as is already done in other chronic diseases [44], may contribute both appropriate and useful for use in clinical practice.

A potential opportunity for questionnaire development exists in the growing use of electronic records and e-health research [45]. To our knowledge, there are not any studies that evaluate the feasibility of e-form QoL questionnaires in MS patients. However, it is not certain that e-form questionnaires would allow for obtaining QoL data in an efficient real-time manner because of the logistics feasibility and the lack of computer stations and hand-held devices [46].

While most QoL questionnaires are initially fixed in content and length, future challenges now focus on the concept of computer adaptive testing. The number of items can be reduced substantially by use of item-response theory and computer adaptive testing to target questions through an iterative process in which responses determine which items are subsequently presented. This approach requires development and validation of algorithms in addition to development and validation of the original questionnaire [12]. Today, the Neurology Quality-of-Life Measurement Initiative is a standardized approach based on extant items used 
A valid QoL measure refers to the extent to which a concept is well founded and corresponds accurately to the

"real world." The validity of a QoL measurement is considered to be the degree to which the tool measures what it

claims to measure.

Three main properties must be explored: reliability, internal validity, and external validity.

\section{Reliability}

The reliability or internal consistency is the extent to which a measurement gives consistent results, that is, the extent with which a set of items in a dimension measures the same attribute. Reliability is assessed by the computation of Cronbach's alpha coefficients. Cronbach's alpha coefficients higher than 0.70 result in satisfactory reliability.

\section{Internal Validity}

Two main aspects must be considered: content validity and construct validity.

(i) Content validity is a nonstatistical type of validity that involves the examination of the questionnaire content to determine whether it covers all the aspects of the domain to be measured.

(ii) Construct validity refers to the extent to which the questionnaires developed from a theory do actually measure what the theory says they do. It mainly relies on statistical analyses of the internal structure of the questionnaire including the relationships between responses to different items. Construct validity was assessed by performing the following.

(A) Exploratory or confirmatory factorial analyses: in the case of confirmatory factorial analysis, a Kaiser-Meyer-Olkin (KMO) measure higher than 0.50 and a total variance higher than $70 \%$ indicate that the number of identified factors (or QoL dimensions) fit to the model.

(B) Rash analysis to explore the unidimensionality of each domain identified: unidimensionality is retained if item goodness-of-fit (INFIT) statistics values range from 0.7 to 1.2 .

(C) Computation of correlation coefficients: correlation coefficients of each item with its dimension (item internal consistency (IIC)) higher than 0.40 and higher than the correlation coefficients of this item with other dimensions (item discriminant validity (IDV)) reflect a satisfactory construct validity.

\section{External validity}

External validity concerns the extent to which the internal construct can be support by external criteria. External validity relies on assessment of the following.

(i) Convergent validity: relationships between the dimensions of the questionnaire and the dimensions of other previously validated questionnaires measuring the same concept.

(ii) Criterion validity: relationships between the dimensions of the questionnaire and other features: sociodemographic or clinical features.

Box 1: Definitions of the main psychometric properties of a QoL measure.

for measuring QoL across common neurologic conditions, including multiple sclerosis, for both adults and children $[47,48]$. This approach allows for comparison of data from different studies.

\section{Key Arguments for the Clinical Utility of the QoL Measure}

The next challenge is to develop credible strategies for integrating QoL data in clinical practice [9]. To enhance the use of QoL measures in clinical decision making, more work is necessary to convince clinicians of the clinical relevance of QoL instruments. Improving knowledge about the determinants of QoL changes and the potential predictive role of QoL on disability may reinforce the conviction of clinicians to use these measures in their MS clinical practice. In the same way, demonstrating that QoL feedback should improve health status of MS patients may confirm the relevance of including QoL in clinical practice.

3.1. Knowledge of QoL Determinants in MS Patients. Clinicians can use QoL assessments to check whether interventions have been as effective from the patient's point of view as from the clinician's, and to determine whether further action is required [2]. Knowledge of which factors are determinants of QoL in patients with MS would assist clinicians in choosing the most appropriate interventions. Several determinants of QoL have been identified with varying strengths of association and include both diseaserelated variables (disability status $[49,50]$, disease duration $[50,51]$, fatigue $[52,53]$, depression $[49,54])$, cognition $[50]$, sociodemographic variables (age and sex $[55,56]$, level of education, and marital status [50]). A number of these factors might be amenable to treatment intervention, which might be expected to improve QoL: fatigue [57], depression [58], and cognition [59].

3.2. Knowledge of the Predictive Role of QoL on Health Status. Predictive factors of long-term disability in patients with MS were also previously reported $[60,61]$ : sociodemographic variables $[62,63]$, initial EDSS score or initial change in EDSS score [61, 64], number or types of relapses [61, 62], nature of the initial symptoms [65], and MRI findings [66]. The weight of these factors is poorly understood and does not explain the entire change of disability that is observed. In contrast to domains such as heart disease and cancer, few studies have examined the predictive value of QoL on 
disability in patients with MS. Longitudinal studies have described whether the QoL level, in addition to conventional clinical and sociodemographic factors, provides prognostic information about the evolution of disability in patients with MS [67-70]. These studies have found that scores of mental health QoL $[67,69]$, scores of "physical-like" dimensions $[68,69,71]$, and the score of global QoL [70] are independent predictors of disability as assessed using the EDSS score. There must be at least one plausible mechanism responsible for the link between poor QoL and progression in disability. QoL could be a more subtle measure of early disability that is not detected by the EDSS scale [70].

The identification of early predictors of the long-term evolution of disability status may be useful to identify both high-risk patients who require early and more aggressive therapies and low-risk patients who could avoid lifelong, expensive, and potentially troublesome treatments. Thus, this identification procedure may favor a more homogeneous selection of patients for clinical therapeutic trials [72]. Patient-reported baseline QoL levels provide additional prognostic information on MS disability beyond traditional clinical or sociodemographic factors. These findings provide strong support for the integration of QoL into clinical practice, in addition to other standard assessments, and reinforce the importance of incorporating a patient's evaluation of their own QoL level during patient monitoring and the assessment of treatment effects. Future studies should provide data from longer follow-up times and will likely highlight other robust findings.

\subsection{The Impact of QoL Feedback to Clinicians in Clinical} Practice. The impact of QoL assessment on health status and other health-related outcomes of patients has already been accomplished in oncology [73-75]. To our knowledge, there are no studies that have explored the effect of assessing QoL in MS care management. The nocebo effect of QoL assessment without feedback should also be considered by clinicians. This effect is defined by the negative expectations that derive from a clinical encounter and lead to poor health outcomes and therapy adherence [76]. This theme constitutes an important avenue of MS research in clinical settings for the coming years.

\section{Difficulties in Interpreting QoL Scores}

In some specific situations, clinicians can be perplexed when interpreting QoL scores: (1) what does a QoL score mean in the absence of normative/reference values? (2) what does a change in QoL score over time mean? and (3) what is the meaning of QoL scores for an individual with cognitive impairment?

4.1. The Lack of Norms in MS QoL Scores. The practical and clinical interpretations of QoL data in a given disorder are difficult unless these data are presented with a reference system. One of the difficulties encountered when interpreting a QoL score for clinicians is the lack of norms values. SF36, a generic instrument, is commonly used because normative data from healthy adults and individuals with a variety of illnesses are available [77]. To our knowledge, no norms were provided for any MS-specific questionnaire. At this time, the QoL scores of the reference population described in the validation publication are implicitly used as norms. It is rare to have scores according to sex, gender, and clinical form. Additionally, it becomes imperative to produce norms for the most popular MS-specific instruments. Aggregating datasets may contribute to produce valid and robust norms. Each patient would be compared to norms.

4.2. The QoL Changes over Time: The Question of Response Shift. Another concern expressed by clinicians is the interpretation of QoL measures in longitudinal studies because QoL, self-reported by the patient, might be influenced by psychological phenomena such as adaptation to illness. Adaptation to illness is a potential explanation in cases where, for example, the QoL of an individual who has experienced a serious health event or chronic condition is similar to the QoL of a healthy individual. Most people with a long-term chronic condition such as MS do not say that physical disability is their primary concern but mention involvement in everyday activities and psychological and emotional well-being [1]. An important mediator of this adaptation process is "response shift" (RS) which involves changing internal standards, values, and the conceptualization of QoL $[78,79]$. These changes do not allow comparing QoL changes over time. RS can be divided into (1) reconceptualization (i.e., a redefinition of QoL), (2) reprioritization (i.e., a change in the importance attributed to component domains constituting QoL), and (3) recalibration (i.e., a change in a patient's internal standards of measurements). True change may be over- or underestimated when RS is present, leading to biased estimates of the magnitude of change. A recent meta-analysis revealed a substantial body of literature on RS phenomena and concluded that RS was common and significant in QoL measurement [80]. Some studies have already investigated this phenomenon in MS populations using the most established methods [78]: the then-test, structural equation modeling (SEM) [81], latent trajectory analysis of residuals [82], recursive partitioning tree analysis as a data mining method [83], and, more recently, the random forest method [84]. Each method has its own specific advantages and limitations that have been clearly discussed [85]. It would be premature to conclude which method is best for detecting RS in MS patients. The variety of methods developed illustrates the complexity and difficulty in detecting RS. Future explorations should be performed to compare the capacity of these methods for detecting RS and the degree of convergence of the isolated phenomena. However, the RS does not necessarily invalidate QoL measures when it appears under the reprioritization component. Change in values may simply represent a mechanism by which people gain true changes in QoL [86]. Determining how to integrate the RS in the interpretation of QoL scores in MS clinical practice is now the next challenge.

4.3. QoL Scores among MS Populations with Cognitive Dysfunction. Prior studies of the relationship between cognitive 
impairment and QoL have been contradictory, highlighting either negligible [87-90] or strong links [51, 91, 92] between cognitive disturbances and QoL alterations. The use of selfreported outcomes in subjects with cognitive dysfunction is of particular concern [93]. The extent to which MS patients with cognitive dysfunction can validly self-report their QoL is a crucial issue that has only partially been examined. While some authors argue that cognitively impaired individuals are unable to produce valid QoL measures [94, 95], others reported empirical evidence suggesting that individuals with a moderate degree of cognitive impairment can perform reliable QoL assessments $[92,96]$. Two recent papers reported data providing strong arguments to support the conclusion that MS patients with executive dysfunction, as determined by the Stroop test [97], and memory dysfunction, as determined by the Grober and Buschke test [98], are reliable and consistent when answering a well-validated MS-specific QoL questionnaire, the MusiQoL $[24,38]$. These studies provided new evidence about the suitability for using self-reported QoL data in these specific populations. The assessment of QoL using the MusiQoL questionnaire could be more widely used without concern over the adequacy of this approach for cognitively impaired patients. However, it has to be acknowledged that a single test of cognitive functioning will never be entirely appropriate. An interdisciplinary approach would be most effective in addressing this deficit $[1,12]$. Future studies should provide similar results according to other definitions of cognitive dysfunction that integrate combinations of different composites (i.e., memory, attention, and concentration) and other QoL questionnaires.

\section{Conclusion}

Using QoL measures may provide clinicians with information regarding the general health status of their MS patients who might otherwise go unrecognized. Neurologists should consider QoL measures in the same way as routine objective measures such as symptomatic evaluation scales, laboratory tests, and radiographs to manage the care of MS patients [46]. In this paper, we discussed several avenues to convince clinicians of the clinical relevance and accuracy of QoL instruments and ultimately to enhance the use of QoL measures in clinical practice for MS patients.

\section{References}

[1] J. G. Noble, L. A. Osborne, K. H. Jones, R. M. Middleton, and D. V. Ford, "Commentary on 'disability outcome measures in multiple sclerosis clinical trials"' Multiple Sclerosis, vol. 18, no. 12, pp. 1718-1720, 2012.

[2] A. J. Mitchell, J. Benito-León, J. M. M. González, and J. Rivera-Navarro, "Quality of life and its assessment in multiple sclerosis: integrating physical and psychological components of wellbeing," Lancet Neurology, vol. 4, no. 9, pp. 556-566, 2005.

[3] A. Solari, "Role of health-related quality of life measures in the routine care of people with multiple sclerosis," Health and Quality of Life Outcomes, vol. 3, article 16, 2005.
[4] Food and Drug Administration, "Guidance for industry: patient reported outcome measures: use in medical product development to support labeling claims," http://www.fda.org/downloads/drugs/.

[5] European Medicines Agency, "Reflection paper on the regulatory guidance for the use of hrqol measures in the evaluation of medicinal products," http://www.ema.europa.eu/ema/pages.

[6] G. Apolone, G. De Carli, M. Brunetti, and S. Garattini, "Healthrelated quality of life (HR-QOL) and regulatory issues: an assessment of the European Agency for the Evaluation of Medicinal Products (EMEA) recommendations on the use of HR-QOL measures in drug approval," PharmacoEconomics, vol. 19, no. 2, pp. 187-195, 2001.

[7] A. Bottomley, D. Jones, and L. Claassens, "Patient-reported outcomes: assessment and current perspectives of the guidelines of the Food and Drug Administration and the reflection paper of the European Medicines Agency," European Journal of Cancer, vol. 45, no. 3, pp. 347-353, 2009.

[8] J. Greenhalgh, A. F. Long, and R. Flynn, "The use of patient reported outcome measures in routine clinical practice: lack of impact or lack of theory?" Social Science and Medicine, vol. 60, no. 4, pp. 833-843, 2005.

[9] A. G. Awad, "Quality-of-life assessment in schizophrenia: the unfulfilled promise," Expert Review of Pharmacoeconomics \& Outcomes Research, vol. 11, no. 5, pp. 491-493, 2011.

[10] P. Auquier and L. Boyer, "Measuring patients' views: between enthusiasm and reality," European Journal Cardio-Thoracic Surgery, vol. 41, no. 4, pp. 829-830, 2012.

[11] L. Boyer and P. Auquier, "The lack of impact of qualityof-life measures in schizophrenia: a shared responsibility?" PharmacoEconomics, vol. 30, no. 6, pp. 531-532, 2012.

[12] J. A. Cohen, S. C. Reingold, C. H. Polman, and J. S. Wolinsky, "Disability outcome measures in multiple sclerosis clinical trials: current status and future prospects," The Lancet Neurology, vol. 11, no. 5, pp. 467-476, 2012.

[13] D. L. Patrick and R. A. Deyo, "Generic and disease-specific measures in assessing health status and quality of life," Medical Care, vol. 27, no. 3, supplement, pp. S217-S232, 1989.

[14] J. A. Freeman, J. C. Hobart, and A. J. Thompson, "Does adding MS-specific items to a generic measure (the SF-36) improve measurement?" Neurology, vol. 57, no. 1, pp. 68-74, 2001.

[15] B. G. Vickrey, R. D. Hays, R. Harooni, L. W. Myers, and G. W. Ellison, "A health-related quality of life measure for multiple sclerosis," Quality of Life Research, vol. 4, no. 3, pp. 187-206, 1995.

[16] D. F. Cella, K. Dineen, B. Arnason et al., "Validation of the functional assessment of multiple sclerosis quality of life instrument," Neurology, vol. 47, no. 1, pp. 129-139, 1996.

[17] S. M. Gold, C. Heesen, H. Schulz et al., "Disease specific quality of life instruments in multiple sclerosis: validation of the Hamburg Quality of Life Questionnaire in Multiple Sclerosis (HAQUAMS)," Multiple Sclerosis, vol. 7, no. 2, pp. 119-130, 2001.

[18] C. E. Ferrans and M. J. Powers, "Psychometric assessment of the quality of life index," Research in Nursing \& Health, vol. 15, no. 1, pp. 29-38, 1992.

[19] J. S. Fischer, N. G. LaRocca, D. M. Miller, P. G. Ritvo, H. Andrews, and D. Paty, "Recent developments in the assessment of quality of life in Multiple Sclerosis (MS)," Multiple Sclerosis, vol. 5, no. 4, pp. 251-259, 1999.

[20] H. L. Ford, E. Gerry, A. Tennant, D. Whalley, R. Haigh, and M. H. Johnson, "Developing a disease-specific quality 
of life measure for people with multiple sclerosis," Clinical Rehabilitation, vol. 15, no. 3, pp. 247-258, 2001.

[21] C. McGuigan and M. Hutchinson, "The multiple sclerosis impact scale (MSIS-29) is a reliable and sensitive measure," Journal of Neurology, Neurosurgery and Psychiatry, vol. 75, no. 2, pp. 266-269, 2004.

[22] G. J. Lankhorst, F. Jelles, R. C. F. Smits et al., "Quality of life in multiple sclerosis: the disability and impact profile (DIP)," Journal of Neurology, vol. 243, no. 6, pp. 469-474, 1996.

[23] C. E. Schwartz, B. F. Cole, and R. D. Gelber, "Measuring patientcentered outcomes in neurologic disease: extending the QTWiST method," Archives of Neurology, vol. 52, no. 8, pp. 754762, 1995.

[24] M. C. Simeoni, P. Auquier, O. Fernandez et al., "Validation of the multiple sclerosis international quality of life questionnaire," Multiple Sclerosis, vol. 14, no. 2, pp. 219-230, 2008.

[25] D. A. Gruenewald, I. J. Higginson, B. Vivat, P. Edmonds, and R. E. Burman, "Quality of life measures for the palliative care of people severely affected by multiple sclerosis: a systematic review," Multiple Sclerosis, vol. 10, no. 6, pp. 690-704, 2004.

[26] D. Bandari, T. L. Vollmer, O. Bhupendra, B. O. Khatri, and T. Tyry, "Quality of life in patients with multiple sclerosis," International Journal of MS Care, vol. 12, pp. 34-41, 2010.

[27] A. G. Awad and L. N. P. Voruganti, "Measuring quality of life in patients with schizophrenia: an update," PharmacoEconomics, vol. 30, no. 3, pp. 183-195, 2012.

[28] E. F. Juniper, G. H. Guyatt, M. Mesbah, and P. Ravaud, Quality of Life and Pharmacoeconomics in Clinical Trials, LippincottRaven, Philadelphia, Pa, USA, 1996.

[29] J. C. Nunnaly and I. C. Bernstein, Psychometric Theory, McGraw-Hill, New York, NY, USA, 1994.

[30] S. P. McKenna, "Measuring quality of life in schizophrenia," European Psychiatry, vol. 12, supplement 3, pp. 267s-274s, 1997.

[31] L. Nicholl, J. C. Hobart, A. F. L. Cramp, and A. S. Lowe-Strong, "Measuring quality of life in multiple sclerosis: not as simple as it sounds," Multiple Sclerosis, vol. 11, no. 6, pp. 708-712, 2005.

[32] S. M. Gold, H. Schulz, H. Stein, K. Solf, K. H. Schulz, and C. Heesen, "Responsiveness of patient-based and external rating scales in multiple sclerosis: head-to-head comparison in three clinical settings," Journal of the Neurological Sciences, vol. 290, no. 1-2, pp. 102-106, 2010.

[33] A. Giordano, E. Pucci, P. Naldi et al., "Responsiveness of patient reported outcome measures in multiple sclerosis relapses: the REMS study," Journal of Neurology, Neurosurgery and Psychiatry, vol. 80, no. 9, pp. 1023-1028, 2009.

[34] A. Riazi, J. C. Hobart, D. L. Lamping, R. Fitzpatrick, and A. J. Thompson, "Evidence-based measurement in multiple sclerosis: the psychometric properties of the physical and psychological dimensions of three quality of life rating scales," Multiple Sclerosis, vol. 9, no. 4, pp. 411-419, 2003.

[35] A. Solari, G. Filippini, L. Mendozzi et al., "Validation of Italian multiple sclerosis quality of life 54 questionnaire," Journal of Neurology Neurosurgery and Psychiatry, vol. 67, no. 2, pp. 158$162,1999$.

[36] J. Füvesi, K. Bencsik, K. Benedek et al., "Cross-cultural adaptation and validation of the 'Multiple Sclerosis Quality of Life Instrument' in Hungarian," Multiple Sclerosis, vol. 14, no. 3, pp. 391-398, 2008.

[37] T. Pekmezovic, D. Kisic Teparcevic, J. Kostic, and J. Drulovic, "Validation and cross-cultural adaptation of the disease-specific questionnaire MSQOL-54 in Serbian multiple sclerosis patients sample," Quality of Life Research, vol. 16, no. 8, pp. 1383-1387, 2007.

[38] K. Baumstarck-Barrau, J. Pelletier, M. C. Simeoni, and P. Auquier, "French validation of the multiple sclerosis international quality of life questionnaire," Revue Neurologique, vol. 167, no. 6-7, pp. 511-521, 2011.

[39] P. Flachenecker, U. Vogel, M. C. Simeoni, P. Auquier, and P. Rieckmann, "MusiQol: international questionnaire investigating quality of life in multiple sclerosis: validation results for the German subpopulation in an international comparison," Der Nervenarzt, vol. 82, no. 10, pp. 1281-1289, 2011.

[40] A. G. Beiske, K. Baumstarck, R. M. Nilsen, and M. C. Simeoni, "Validation of the multiple sclerosis international quality of life (MusiQoL) questionnaire in Norwegian patients," Acta Neurologica Scandinavica, vol. 125, no. 3, pp. 171-179, 2011.

[41] O. Fernandez, V. Fernandez, K. Baumstarck-Barrau et al., "Validation of the spanish version of the multiple sclerosis international quality of life (musiqol) questionnaire," $B M C$ Neurology, vol. 11, article 127, 2011.

[42] J. J. Gutteling, J. J. V. Busschbach, R. A. de Man, and S. E. Darlington, "Logistic feasibility of health related quality of life measurement in clinical practice: results of a prospective study in a large population of chronic liver patients," Health and Quality of Life Outcomes, vol. 6, article 97, 2008.

[43] J. Morris, D. Perez, and B. McNoe, "The use of quality of life data in clinical practice," Quality of Life Research, vol. 7, no. 1, pp. 85-91, 1998.

[44] L. Boyer, M. C. Simeoni, A. Loundou et al., "The development of the S-QoL 18: a shortened quality of life questionnaire for patients with schizophrenia," Schizophrenia Research, vol. 121, no. 1-3, pp. 241-250, 2010.

[45] D. V. Ford, K. H. Jones, R. M. Middleton et al., "The feasibility of collecting information from people with Multiple Sclerosis for the UK MS Register via a web portal: characterising a cohort of people with MS," BMC Medical Informatics and Decision Making, vol. 12, article 73, 2012.

[46] M. Y. Halyard, M. H. Frost, A. Dueck, and J. A. Sloan, "Integrating QOL assessments for clinical and research purposes," Current Problems in Cancer, vol. 30, no. 6, pp. 319-330, 2006.

[47] D. Cella, J. S. Lai, C. J. Nowinski et al., "Neuro-QOL: brief measures of health-related quality of life for clinical research in neurology," Neurology, vol. 78, no. 23, pp. 1860-1867, 2012.

[48] R. C. Gershon, J. S. Lai, R. Bode et al., "Neuro-QOL: quality of life item banks for adults with neurological disorders: item development and calibrations based upon clinical and general population testing," Quality of Life Research, vol. 21, no. 3, pp. 475-486, 2012.

[49] I. S. Lobentanz, S. Asenbaum, K. Vass et al., "Factors influencing quality of life in multiple sclerosis patients: disability, depressive mood, fatigue and sleep quality," Acta Neurologica Scandinavica, vol. 110, no. 1, pp. 6-13, 2004.

[50] O. Fernandez, K. Baumstarck-Barrau, M. C. Simeoni, and P. Auquier, "Patient characteristics and determinants of quality of life in an international population with multiple sclerosis: assessment using the MusiQoL and SF-36 questionnaires," Multiple Sclerosis, vol. 17, no. 10, pp. 1238-1249, 2011.

[51] J. Benito-León, J. M. Morales, and J. Rivera-Navarro, "Healthrelated quality of life and its relationship to cognitive and emotional functioning in multiple sclerosis patients," European Journal of Neurology, vol. 9, no. 5, pp. 497-502, 2002.

[52] L. A. C. Nogueira, F. R. Nóbrega, K. N. Lopes, L. C. S. Thuler, and R. M. P. Alvarenga, "The effect of functional limitations and 
fatigue on the quality of life in people with multiple sclerosis," Arquivos de Neuro-Psiquiatria, vol. 67, no. 3, pp. 812-817, 2009.

[53] S. Pittion-Vouyovitch, M. Debouverie, F. Guillemin, N. Vandenberghe, R. Anxionnat, and H. Vespignani, "Fatigue in multiple sclerosis is related to disability, depression and quality of life," Journal of the Neurological Sciences, vol. 243, no. 1-2, pp. 39-45, 2006.

[54] M. P. Amato, G. Ponziani, F. Rossi, C. L. Liedl, C. Stefanile, and L. Rossi, "Quality of life in multiple sclerosis: the impact of depression, fatigue and disability," Multiple Sclerosis, vol. 7, no. 5, pp. 340-344, 2001.

[55] I. Casetta, T. Riise, M. Wamme Nortvedt et al., "Gender differences in health-related quality of life in multiple sclerosis," Multiple Sclerosis, vol. 15, no. 11, pp. 1339-1346, 2009.

[56] N. Pfaffenberger, K. P. Pfeiffer, M. Deibl, S. Höfer, V. Günther, and H. Ulmer, "Association of factors influencing health-related quality of life in MS," Acta Neurologica Scandinavica, vol. 114, no. 2, pp. 102-108, 2006.

[57] M. A. Plow, M. Finlayson, R. W. Motl, and F. Bethoux, "Randomized controlled trial of a teleconference fatigue management plus physical activity intervention in adults with multiple sclerosis: rationale and research protocol," BMC Neurology, vol. 12, no. 1, article 122, 2012.

[58] R. E. Boeschoten, J. Dekker, B. M. Uitdehaag et al., "Internetbased self-help treatment for depression in multiple sclerosis: study protocol of a randomized controlled trial," BMC Psychiatry, vol. 12, no. 1, article 137, 2012.

[59] E. M. Rosti-Otajarvi and P. I. Hamalainen, "Neuropsychological rehabilitation for multiple sclerosis," Cochrane Database of Systematic Reviews, no. 11, Article ID CD009131, 2011.

[60] M. Debouverie, S. Pittion-Vouyovitch, H. Brissart, and F. Guillemin, "Physical dimension of fatigue correlated with disability change over time in patients with multiple sclerosis," Journal of Neurology, vol. 255, no. 5, pp. 633-636, 2008.

[61] R. A. Rudick, J. C. Lee, G. R. Cutter et al., "Disability progression in a clinical trial of relapsing-remitting multiple sclerosis eightyear follow-up," Archives of Neurology, vol. 67, no. 11, pp. 1329$1335,2010$.

[62] M. Eriksson, O. Andersen, and B. Runmarker, "Long-term follow up of patients with clinically isolated syndromes, relapsingremitting and secondary progressive multiple sclerosis," Multiple Sclerosis, vol. 9, no. 3, pp. 260-274, 2003.

[63] A. Langer-Gould, R. A. Popat, S. M. Huang et al., "Clinical and demographic predictors of long-term disability in patients with relapsing-remitting multiple sclerosis: a systematic review," Archives of Neurology, vol. 63, no. 12, pp. 1686-1691, 2006.

[64] L. V. Bosma, J. J. Kragt, D. L. Knol, C. H. Polman, and B. M. Uitdehaag, "Clinical scales in progressive MS: predicting longterm disability," Multiple Sclerosis, vol. 18, no. 3, pp. 345-350, 2012.

[65] T. Gholipour, B. Healy, N. F. Baruch, H. L. Weiner, and T. Chitnis, "Demographic and clinical characteristics of malignant multiple sclerosis," Neurology, vol. 76, no. 23, pp. 1996-2001, 2011.

[66] D. K. B. Li, U. Held, J. Petkau et al., "MRI T2 lesion burden in multiple sclerosis: a plateauing relationship with clinical disability," Neurology, vol. 66, no. 9, pp. 1384-1389, 2006.

[67] M. W. Nortvedt, T. Riise, K. M. Myhr, and H. I. Nyland, "Quality of life as a predictor for change in disability in MS," Neurology, vol. 55, no. 1, pp. 51-54, 2000.
[68] M. A. J. Visschedijk, B. M. J. Uitdehaag, M. Klein et al., "Value of health-related quality of life to predict disability course in multiple sclerosis," Neurology, vol. 63, no. 11, pp. 2046-2050, 2004.

[69] J. B. Guarnaccia, M. Aslan, T. Z. O’Connor et al., "Quality of life for veterans with multiple sclerosis on disease-modifying agents: relationship to disability," Journal of Rehabilitation Research and Development, vol. 43, no. 1, pp. 35-44, 2006.

[70] J. Benito-Leon, A. J. Mitchell, J. Rivera-Navarro, and J. M. Morales-Gonzalez, "Impaired health-related quality of life predicts progression of disability in multiple sclerosis," European Journal of Neurology, vol. 20, no. 1, pp. 79-86, 2012.

[71] K. Baumstarck, J. Pelletier, H. Butzkueven et al., "Healthrelated quality of life as an independent predictor of longterm disability for patients with relapsing-remitting multiple sclerosis," European Journal of Neurology, 2013.

[72] R. Bergamaschi, S. Quaglini, M. Trojano et al., "Early prediction of the long term evolution of multiple sclerosis: the Bayesian Risk Estimate for Multiple Sclerosis (BREMS) score," Journal of Neurology, Neurosurgery and Psychiatry, vol. 78, no. 7, pp. 757759, 2007.

[73] E. E. Takeuchi, A. Keding, N. Awad et al., "Impact of patientreported outcomes in oncology: a longitudinal analysis of patient-physician communication," Journal of Clinical Oncology, vol. 29, no. 21, pp. 2910-2917, 2011.

[74] G. Velikova, L. Booth, A. B. Smith et al., "Measuring quality of life in routine oncology practice improves communication and patient well-being: a randomized controlled trial," Journal of Clinical Oncology, vol. 22, no. 4, pp. 714-724, 2004.

[75] S. B. Detmar, M. J. Muller, J. H. Schornagel, L. D. V. Wever, and N. K. Aaronson, "Health-related quality-of-life assessments and patient-physician communication: a randomized controlled trial," Journal of the American Medical Association, vol. 288, no. 23, pp. 3027-3034, 2002.

[76] L. Colloca and D. Finniss, "Nocebo effects, patient-clinician communication, and therapeutic outcomes," Journal of the American Medical Association, vol. 307, no. 6, pp. 567-568, 2012.

[77] A. Leplege, E. Ecosse, J. Pouchot, J. Coste, and T. V. Perneger, MOS SF36 Questionnaire. Manual and Guidelines for Scores' Interpretation, Estem, Vernouillet, France, 2001.

[78] M. A. G. Sprangers and C. E. Schwartz, "Integrating response shift into health-related quality of life research: a theoretical model," Social Science and Medicine, vol. 48, no. 11, pp. 1507$1515,1999$.

[79] C. E. Schwartz and M. A. G. Sprangers, "Methodological approaches for assessing response shift in longitudinal healthrelated quality-of-life research," Social Science and Medicine, vol. 48, no. 11, pp. 1531-1548, 1999.

[80] C. E. Schwartz, R. Bode, N. Repucci, J. Becker, M. A. G. Sprangers, and P. M. Fayers, "The clinical significance of adaptation to changing health: a meta-analysis of response shift," Quality of Life Research, vol. 15, no. 9, pp. 1533-1550, 2006.

[81] B. L. King-Kallimanis, F. J. Oort, S. Nolte, C. E. Schwartz, and M. A. Sprangers, "Using structural equation modeling to detect response shift in performance and health-related quality of life scores of multiple sclerosis patients," Quality of Life Research, vol. 20, no. 10, pp. 1527-1540, 2011.

[82] S. Ahmed, N. Mayo, S. Scott, A. Kuspinar, and C. Schwartz, "Using latent trajectory analysis of residuals to detect response shift in general health among patients with multiple sclerosis," Quality of Life Research, vol. 20, no. 10, pp. 1555-1560, 2011. 
[83] Y. Li and C. E. Schwartz, "Data mining for response shift patterns in multiple sclerosis patients using recursive partitioning tree analysis," Quality of Life Research, vol. 20, no. 10, pp. 15431553, 2011.

[84] M. Boucekine, A. Loundou, R. L'Mouaci et al., "Understanding response shit in multiple sclerosis patients: application of Random Forest method," Quality of Life Research, vol. 21, supplement 1, p. 32, 2012, ISOQOL 20th Annual Conference of the International Society for Quality of Life Research, Budapest, Hungary, October 2012.

[85] C. E. Schwartz, M. A. Sprangers, F. Oort et al., "Response shift in patients with multiple sclerosis: an application of three statistical techniques," Quality of Life Research, vol. 20, no. 10, pp. 1561-1572, 2011.

[86] P. A. Ubel, Y. Peeters, and D. Smith, "Abandoning the language of "response shift": a plea for conceptual clarity in distinguishing scale recalibration from true changes in quality of life," Quality of Life Research, vol. 19, no. 4, pp. 465-471, 2010.

[87] S. M. Rao, G. J. Leo, L. Bernardin, and F. Unverzagt, "Cognitive dysfunction in multiple sclerosis. I. Frequency, patterns, and prediction,” Neurology, vol. 41, no. 5, pp. 685-691, 1991.

[88] S. R. Montel and C. Bungener, "Coping and quality of life in one hundred and thirty five subjects with multiple sclerosis," Multiple Sclerosis, vol. 13, no. 3, pp. 393-401, 2007.

[89] B. I. Glanz, B. C. Healy, D. J. Rintell, S. K. Jaffin, R. Bakshi, and H. L. Weiner, "The association between cognitive impairment and quality of life in patients with early multiple sclerosis," Journal of the Neurological Sciences, vol. 290, no. 1-2, pp. 75-79, 2010.

[90] K. Baumstarck-Barrau, M. C. Simeoni, F. Reuter et al., "Cognitive function and quality of life in multiple sclerosis patients: a cross-sectional study," BMC Neurology, vol. 11, no. 1, article 17, 2011.

[91] D. M. Miller, R. A. Rudick, M. Baier et al., "Factors that predict health-related quality of life in patients with relapsing-remitting multiple sclerosis," Multiple Sclerosis, vol. 9, no. 1, pp. 1-5, 2003.

[92] S. M. Gold, H. Schulz, A. Mönch, K. H. Schulz, and C. Heesen, "Cognitive impairment in multiple sclerosis does not affect reliability and validity of self-report health measures," Multiple Sclerosis, vol. 9, no. 4, pp. 404-410, 2003.

[93] R. P. Riemsma, C. A. Forbes, J. M. Glanville, A. J. Eastwood, and J. Kleijnen, "General health status measures for people with cognitive impairment: learning disability and acquired brain injury," Health Technology Assessment, vol. 5, no. 6, pp. 1-100, 2001.

[94] Y. Goverover, N. Chiaravalloti, and J. DeLuca, "The relationship between self-awareness of neurobehavioral symptoms, cognitive functioning, and emotional symptoms in multiple sclerosis," Multiple Sclerosis, vol. 11, no. 2, pp. 203-212, 2005.

[95] R. H. B. Benedict, D. Cox, L. L. Thompson, F. Foley, B. Weinstock-Guttman, and F. Munschauer, "Reliable screening for neuropsychological impairment in multiple sclerosis," Multiple Sclerosis, vol. 10, no. 6, pp. 675-678, 2004.

[96] R. A. Marrie, D. M. Miller, G. J. Chelune, and J. A. Cohen, "Validity and reliability of the MSQLI in cognitively impaired patients with multiple sclerosis," Multiple Sclerosis, vol. 9, no. 6, pp. 621-626, 2003.

[97] K. Baumstarck, J. Pelletier, V. Aghababian et al., "Is the concept of quality of life relevant for multiple sclerosis patients with cognitive impairment? Preliminary results of a cross-sectional study," Plos One, vol. 7, no. 1, Article ID e30627, 2012.
[98] K. Baumstarck, F. Reuter, M. Boucekine et al., "Relevance of quality of life assessment for multiple sclerosis patients with memory impairment," Plos One, vol. 7, no. 12, Article ID e50056, 2012. 


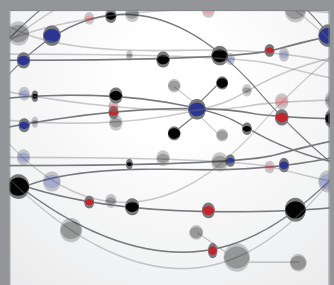

The Scientific World Journal
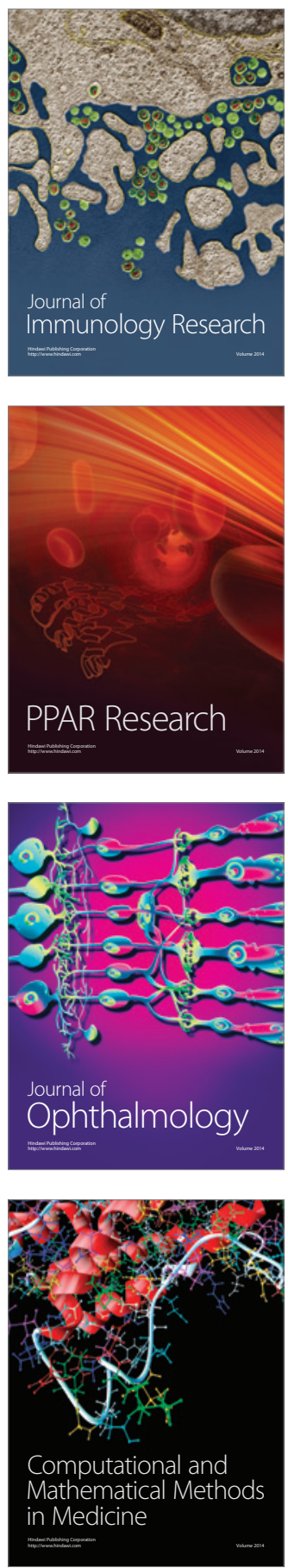

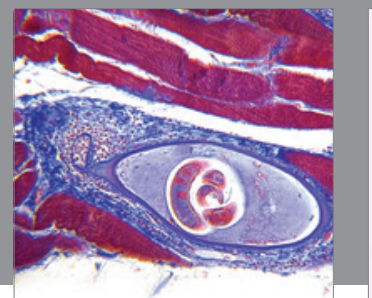

Gastroenterology

Research and Practice
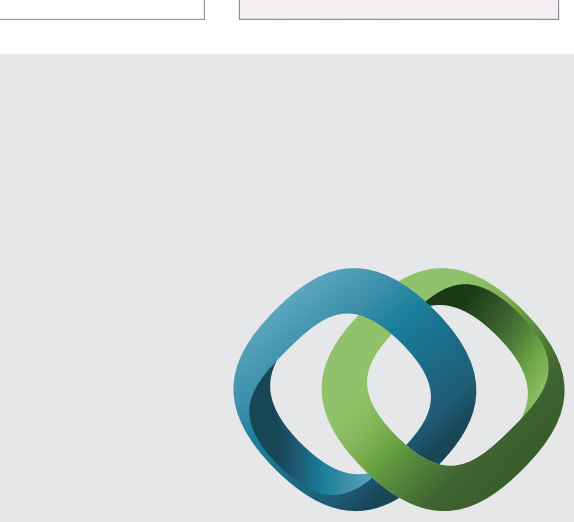

\section{Hindawi}

Submit your manuscripts at

http://www.hindawi.com
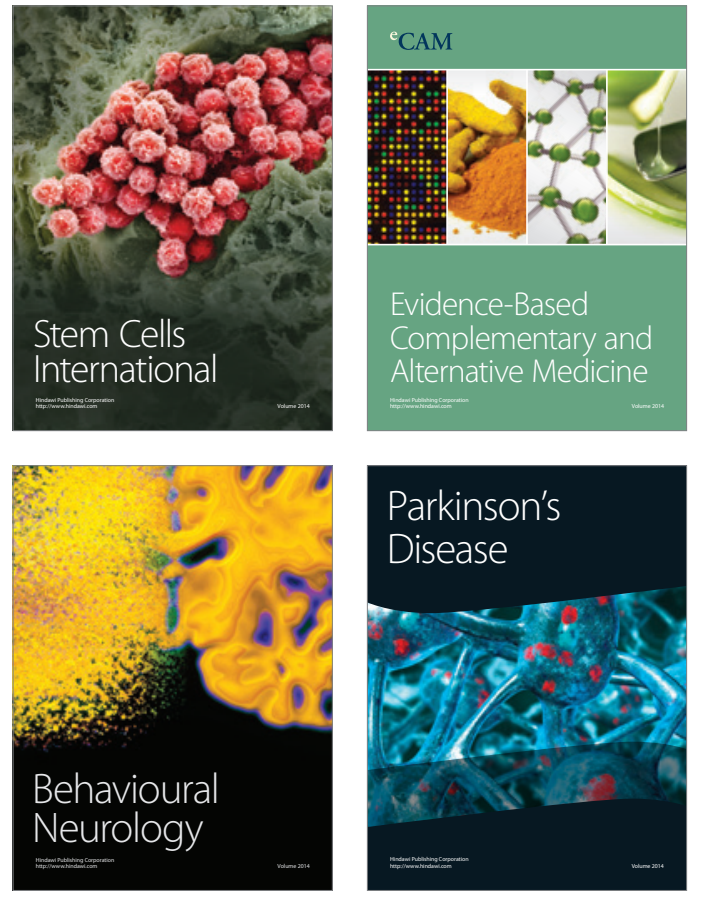
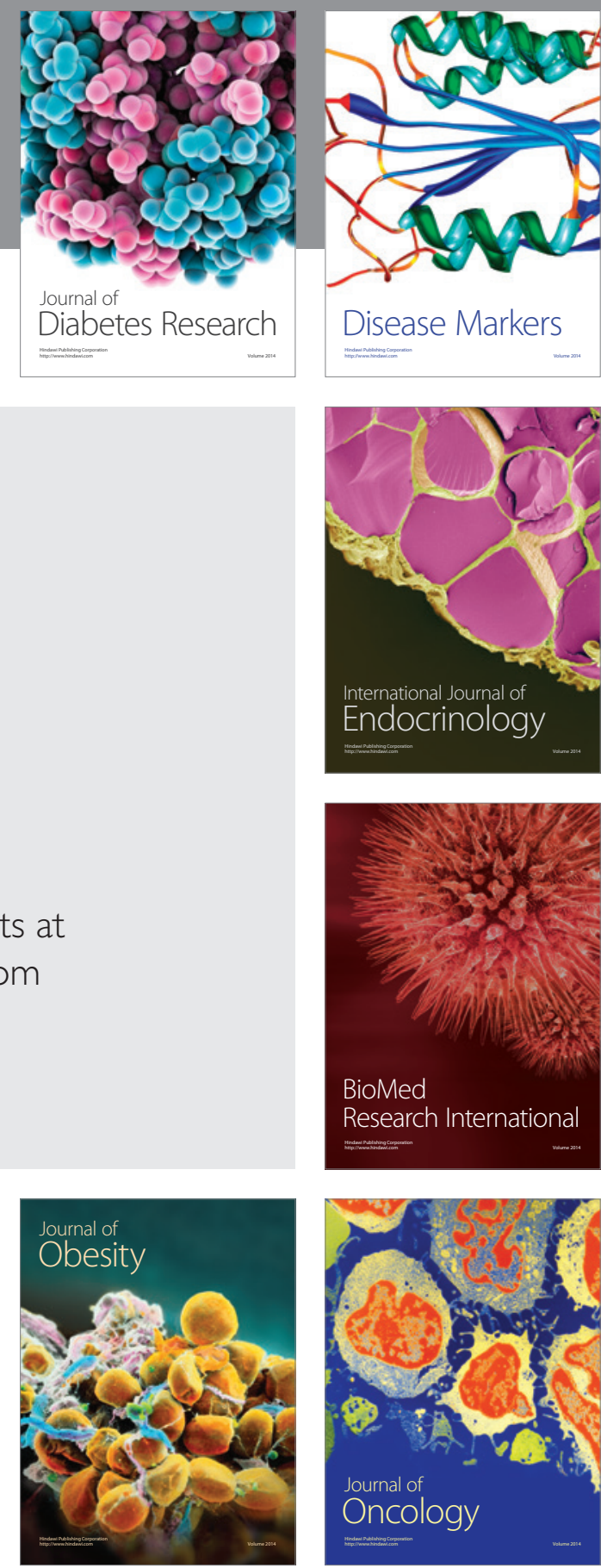

Disease Markers
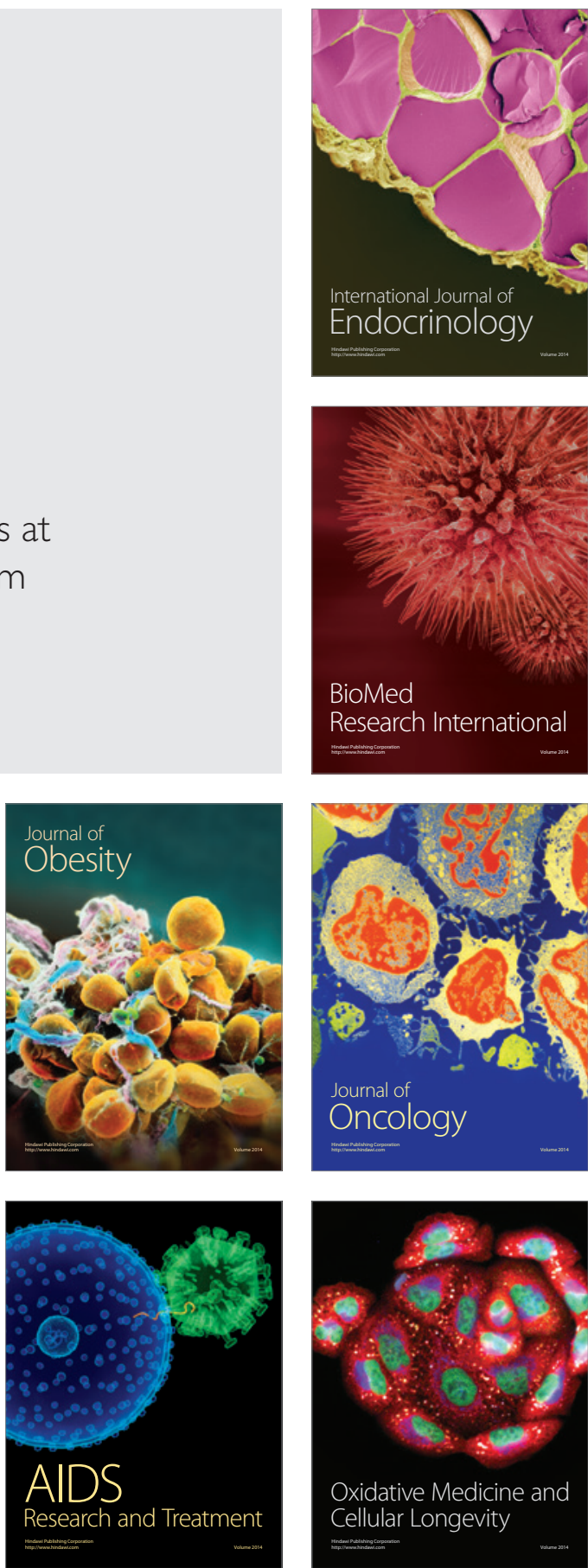